This item was submitted to Loughborough's Research Repository by the author.

Items in Figshare are protected by copyright, with all rights reserved, unless otherwise indicated.

\title{
Subjective responses to display bezel characteristics
}

PLEASE CITE THE PUBLISHED VERSION

http://dx.doi.org/10.1016/j.apergo.2014.10.005

\section{PUBLISHER}

(C) Elsevier Science Ltd

\section{VERSION}

AM (Accepted Manuscript)

\section{PUBLISHER STATEMENT}

This work is made available according to the conditions of the Creative Commons Attribution-NonCommercialNoDerivatives 4.0 International (CC BY-NC-ND 4.0) licence. Full details of this licence are available at: https://creativecommons.org/licenses/by-nc-nd/4.0/

\section{LICENCE}

CC BY-NC-ND 4.0

\section{REPOSITORY RECORD}

Howarth, Peter A., and S.G. Hodder. 2019. "Subjective Responses to Display Bezel Characteristics". figshare. https://hdl.handle.net/2134/18680. 


\title{
Subjective Responses to Display Bezel Characteristics
}

\author{
Peter A. Howarth* and Simon G. Hodder \\ Environmental Ergonomics Research Centre \\ Loughborough Design School \\ Loughborough University, LE11 3TU \\ United Kingdom \\ * Communicating Author: p.a.howarth@lboro.ac.uk; (44) 1509223040
}

\begin{abstract}
High quality flat panel computer displays (FPDs) with high resolution screens are now commonplace, and black, grey, white, beige and silver surrounds ('bezels'), matt or glossy, are in widespread use. It has been suggested that bezels with high reflectance, or with a high gloss, could cause eyestrain, and we have investigated this issue. Twenty office workers (unaware of the study purpose) used six different FPDs, for a week each, at their own desk. These displays were identical apart from the bezel colour (black, white or silver) and shininess (matt or glossy). Participants completed questionnaires about their visual comfort at the end of each week, and were fully debriefed in lunch-time focus groups at the end of the study. For the white and the silver bezels, the glossiness of the bezel was not an issue of concern. The participants were significantly less content with the glossy black surround than with the matt black surround, and in general the glossy black bezel was the least-liked of all those used. With the possible exception of this surround, there was no evidence of significantly increased visual discomfort, indicative of eyestrain, as a result of high or low bezel reflectance, or of high glossiness.
\end{abstract}


KEYWORDS : FPDs ${ }^{1}$, Bezel, Gloss, Glare.

\section{INTRODUCTION}

Flat panel displays (FPDs) with high resolution screens are now common in the workplace. As with tablets, style has played an important role in the marketplace, and black, grey, white, beige and silver surrounds ('bezels'), matt or glossy, are common. However, concerns linger that some of these could be detrimental from an ergonomic viewpoint, leading to eyestrain for the user.

The question of whether bezel characteristics adversely affect people is important because there are moves to limit their design ${ }^{2}$, which are based on concerns about the health and safety of people using the display. This is despite the fact that there is little scientific evidence to indicate why, or how, reflectance or glossiness could actually affect users. In 2003 the Swedish Confederation of Professional Employees (TCO) stated (Overödder and Rudling [2003a]) that "If a dark frame is used with flat displays in common office lighting, the display-to-frame contrast can cause eye strain". TCO concluded, presumably on the basis of their own studies, that "black frames can be a problem due to excessive contrast ..” and that “... white frames are considered a problem due to excessively high reflectance” [Overödder and Rudling, 2003b]. No data were published to substantiate these claims at the time, although a subsequent study performed at TCO (Belánd and Andrén, 2008) indicated that higher gloss bezels were less acceptable than those with lower gloss, with the reflections in the higher gloss frame being 'disturbing'. The suggestion has been made that

1 In this paper we use the following terms with these specific meanings:

Display: the complete piece of hardware which makes up a computer monitor, including the screen and the case

Screen: the active part of a display device

Cathode Ray Tube (CRT): the complete display device using this screen technology

Flat Panel Display (FPD): the complete display device incorporating Flat Panel technology

Bezel: the portion of the display immediately adjacent to the screen 
poorly-designed bezels could contribute to so-called "computer vision syndrome” (Yan et al. 2008) and potentially this could, to some degree, affect millions of people at work.

Other studies to date [Soderston et al. 2003, Hunter, Boyce and Watt, 2003, Howarth and Hodder, 2004, Sheedy et al. 2005, Hisatake et al. 2011] present the opposite view and indicate that the bezel characteristics do not affect either performance or comfort. However, these studies can all be criticised (as can that of Belánd and Andrén, 2008) on the grounds that they were laboratory studies of restricted time and scope, and did not examine the effect of bezel colour or gloss during normal work. The current study avoids this pitfall as it examined participants using a number of different displays for a week at a time in their own workplace.

We provide evidence here that office workers, rather than test panel subjects, were not disturbed by either the glossiness of the surround, or its colour (black, white or silver) with the possible exception of a glossy black bezel. Also, importantly, there was no evidence of a difference in visual discomfort between the different conditions.

\section{METHODS}

\section{Conditions}

The study was run over a four month period, during the mid and late summer of 2003. Twenty participants, none of whom were aware of the study purpose, each sat at their own desk with one of the six FPDs replacing their own VDU for a full week. At the end of the week they completed a questionnaire about the display and the screen, and the display was then changed. In order to

\footnotetext{
${ }^{2}$ ISO/TC 159/SC4/WG2
} 
ensure that there were no order effects, participants were presented with the FPDs in a pseudorandom order, designed to ensure that, as far as was practicable, each FPD was viewed the same number of times before and after every other FPD. Before starting the study, participants rated the VDU that they normally used, which in all cases was a CRT. This initial step was designed to familiarize the participants with the questionnaire and the procedure, and to ensure that primacy effects did not affect the FPD assessments.

\section{Participants}

All participants were secretarial, managerial, or research staff of Loughborough University, from either the Department of Human Sciences or the English Language Study Unit. They ranged in age from 20 to 59 . 7 were male and 13 were female, and all used computers extensively during their daily routine.

\section{Displays}

The Flat Panel Displays were all 17 inch LCD monitors manufactured by Samsung, each with a resolution of $1280 * 1024$. The manufacturer produces low-gloss silver or black bezels, and to extend the study we purchased extra displays which were then painted white. One display of each bezel colour (white, black, silver) was painted with clear varnish to provide a glossy appearance. All displays were driven by the participants' own PC using MS Windows. All of the screens appeared to be identical, the only difference between the displays being the colour and glossiness of the bezel. Participants were instructed to adjust the display when they received it, and to set it to their own preference. Figure 1 shows the two silver FPD's, illustrating the difference in the bezel glossiness. 
Gloss was measured using a Minolta Multi-Gloss 268, serial \#192646, at a measurement angle of 60 degrees, and reflectance was measured using a Minolta LS-110, serial \# 79123002 and a standard white reflectance comparison sheet (see Table 1).

\section{INSERT TABLE 1 ABOUT HERE}

\section{Questionnaire}

The questionnaire contained twenty-nine questions, of which only seven were relevant here:

1. How irritated and disturbed visually did you usually feel when looking at the screen?

2. How legible did you consider the text to be?

3. How much visual discomfort did you experience during the trial?

4. Was the level of discomfort greater than or less than that which you usually experience with screen work?

5. How content were you with the visual appearance of the complete monitor which you have been using?

6. How pleasant did you find the glossiness of the bezel?

7. How disturbing did you find the glossiness of the bezel?

For each of the first five of the above questions participants were presented with a horizontal line, anchored by descriptive end points (e.g. completely content; not at all content). This approach mirrors that used by Schenkman et al., (1999) although some questions were phrased slightly differently to make them more intuitively understandable. For the sixth question, participants had to choose one of five categories for their response, and for the seventh question they had to choose one of four categories. These last two questions, about glossiness, were embedded amongst a number of superfluous questions, included to disguise the importance of gloss to the study (e.g. "How disturbing did you find reflections from the furniture”). This 'masking' was designed to ensure that 
participants would not be 'prompted' to pay attention specifically to the bezel glossiness, thereby possibly biasing their results. It was important that the participants remained unaware of this issue because they needed to assess all six displays, and learning of its importance early in the study could have affected later responses. Consequently, they were not told that the only questions of interest were those about bezel glossiness, nor that the other questions were there simply to mask the true item of interest in the study. For the same reason, the two questions which deal with “eyestrain”, or visual discomfort, were also embedded amongst other questions.

Following the end of their trials, participants were debriefed in lunchtime focus groups of six or seven people, and as part of the process they were informed about the real purpose of the study. None of the participants were paid, but they were all provided with a free lunch during the debriefing. 


\section{RESULTS}

The black bezels both had a reflectance below $20 \%$ and the white bezels both had a reflectance above $80 \%$ (Table 1). The glossy bezels were all above 30 gloss units and the matt bezels were all below it. The silver matt FPD was thus the only display to meet both of the criteria for gloss and reflectance specified by TCO at the time (TCO’03).

The mean (+/- 1 sem.) results for the twenty participants for each of the seven questions are shown, in order, in figure 2.

\section{INSERT FIGURE 2 ABOUT HERE}

It is clear that there is little to choose between the different displays, with the exception of the display incorporating the glossy black bezel. This display was consistently, on average, rated less positively than the others - a difference that was statistically significant at the $0.01 \%$ criterion level for most of the questions (Wilcoxon test). Occasional statistical significance was found when comparing other conditions, for example on question 5 both silver screens were rated significantly better than either of the white screens. Having said this, it must be accepted that any differences were small, and indeed although the glossy black was rated by far the most disturbing in question 6 , it was still only classified as 'slightly' disturbing on average.

\section{INSERT TABLE 2 ABOUT HERE}

The full set of results are tabulated in Table 2, and the individual responses for the question "How much visual discomfort did you experience during the trial” are shown in Figure 3. There is considerable variation across the sample not only in the patterns seen in each panel, but also in the rating of each bezel. To take the example of the silver matt bezel, one person rated it as zero (no discomfort) whilst another rated it as 7 , where 10 is extreme discomfort. 
For the white and the silver displays, there was little difference between the results for the matt finish and those for the glossy finish, and indeed the variation between the responses to the two surface finishes appeared to be smaller than the differences between bezel colours when the black was included in the comparison.

\section{DISCUSSION}

There are no theoretical grounds to expect visual performance at a FPD to be affected by either the glossiness or the colour of the bezel, on either a physiological or a physical basis [Howarth and Hodder, 2004, Sheedy et al. 2005]. In our previous study (Howarth and Hodder, 2004) we found no effect, but we were aware that this result did not necessarily constitute proof as it is also consistent with missing an effect that does exist. Consequently, we went on show that the physical condition needed to produce a performance decrement were well outside the range of conditions likely to be found in any normal office or home environment. Similarly, there are no theoretical reasons to expect direct discomfort on physiological grounds. On the other hand, it is quite possible that reflections in a bezel could cause distraction and annoyance, which could indirectly affect performance and well-being.

Consistent with our expectations on theoretical grounds, the empirical findings reported here show clearly that, for high-reflectance bezels, glossiness is not, in fact, a major factor in determining whether a display is acceptable or not to the user. It is clear that there is no particular pattern to the data, and, with the exception of the black glossy display, no single configuration was thought overall to be better or worse than the others. This conclusion is in agreement with the findings of our previous, laboratory study, [Howarth and Hodder, 2004] which found no difference in visual performance or comfort as a consequence of bezel gloss, and is in agreement with other studies 
[Soderston et al. 2003; Hunter, Boyce and Watt, 2003]. Furthermore, our results indicate that distraction and annoyance produced by reflections in a bezel is not a serious problem in the workplace, as has recently been claimed (KAN 2011).

Looking at the responses to individual questions, by far the most important finding, in the context of health and safety, is the lack of appreciable variation in the responses to Questions 3 and 4 for the different displays. If either the glossiness or the reflectance were to influence eyestrain, one would expect this to be reflected in increased reports of visual discomfort. In particular, one would expect all of the displays to produce more discomfort than the silver matt display, which conformed with the TCO guidelines which were current at the time (TCO’03). However, the responses to these first two questions indicate that any difference present was trivial. Note, in particular, the answers for Question 4 in which the glossy silver bezel performed better than the matt silver bezel, a result which is the opposite of that seen in the responses to Question 3. This is precisely the picture one would expect to see if there were no difference between the two displays, but there was random variation in the participants' responses.

In examining the results one needs to be aware of the presence of a 'halo' effect, as revealed by the answers to question 2. In each case the screen was identical, and the text was equally legible. Thus there should have been no difference between the responses on this question for any of the six conditions. The 'halo effect', in this context, is the unconscious raising of the rating of an attribute (here, the clarity of the text) on the basis, not of that attribute itself, but of an overall positive response to the object (here, the overall appearance of the display). It seems likely that the fact that the two black-surround screens performed the worst is indicative of a 'reverse halo' effect, where the response to the question is influenced by a relative dislike of the bezel colour, on average, in comparison with the others. If there is, indeed, such an influence then one has to view the answers to individual questions with caution. 
Glossiness was not a problem for our participants, in contrast with those tested by Belánd and Andrén (2008), who reported that their participants found the reflections disturbing. There were a number of differences between the studies which could explain this discrepancy. The first is that our participants were unaware of the purpose of the study, and so were not 'primed' in any way. The discussion which took place in the focus groups revealed that all but one of the participants had been unaware that half of the displays had a glossy bezel and the others had a matt bezel. Once the participants had been told the true purpose of the study, none expressed any dissatisfaction with any of the FPDs on the grounds of the bezel glossiness, although there were differences in opinion about the desirability and acceptability of different bezel colours. The second difference between the studies is in the time allocated for the use of the screens - our participants had each screen for a week, whereas those of Belánd and Andrén only had each for 2 minutes. Having not only been primed about the existence of reflections in the bezel, but also having been given the expectation that these might be disturbing, it is perhaps not surprising that this is what the participants reported. However, the user's comfort over time must be more important than their immediate response, and our results indicate that if our participants were indeed disturbed by bezel reflections initially then any concern dissipated over time. Third, we did not use an artificial set-up using a head-rest, and it is quite likely that if our participants encountered any annoying reflections initially they simply adjusted their position, or that of the screen - an option available to everyone in the workplace normally, but one that was denied the participants in Belánd and Andrén’s study. Furthermore, the artificial set-up used in their study could have changed the normal appearance of the displays (Obein et al. 2004, Marlow et al. 2011).

Finally, it is not clear exactly what Belánd and Andrén’s participants were reporting. Although the authors say they were looking at the effects on "user comfort” (p.230) this is not what participants were asked to evaluate, and the question asked was whether or not the reflection was "disturbing”. 
For some participants the presence of any reflection was "disturbing" and it is hard to see how such reports reflect a lack of "comfort" in the usual meaning of the word. On the other hand, it is easy to see how if one has a preference for a bezel that is free from any noticeable reflection then one might report the presence of one that is pointed out as "disturbing". To put this into perspective, presumably the presence of a manufacturer's logo, or a visible label signifying that the screen meets certain standards, or an LED indicating that there is power getting to the display, would be no less “disturbing” when it was pointed out to someone who objected to it.

It is important to be aware that the wide range of conditions employed in our study (twenty different locations) allowed for the identification of problems that may only have been present under certain circumstances, such as the display being located disadvantageously with respect to other light sources in the environment (e.g. overhead lamps). The fact that none of the 20 individuals reported any problems with any of the 6 displays (120 different trials), either at the time or in the focus group, indicates that either any such problems were trivial in nature, or else when the participants set up the displays they did so in a way that avoided reflections being seen by the eye.

Finally, it is quite clear from our results that, in the context of acceptability, reflectance and gloss are not independent. The black, white and silver glossy bezels all had similar gloss values, but very different acceptability. It is to be expected that the higher the reflectance the more acceptable a given amount of gloss will be because the contrast between any reflection and the portion of the bezel surrounding it will be lower. Thus, reflections that are obvious in a glossy black bezel may be quite inconspicuous in a glossy white, or silver, one. We have seen a similar picture in our previous study (Howarth and Hodder 2004) in which we used a stainless steel surround to provide a mirrorlike bezel. Although informal discussion revealed that most people thought this bezel to be attractive in appearance, there was an appreciable range of opinions about its appropriateness for use in an office environment. 
In summary, we see no reason from our own results to limit the colour or reflectance of the surround to a computer display. Specifically, we have no evidence that there is any health hazard, inasmuch as we found no evidence of differential amounts of eyestrain which was linked to either bezel reflectance or gloss. Although the glossy black surround was the least-liked, not a single participant stated that they would not be prepared to have it on their desk. Indeed, some participants rated this the best of the displays, indicating that personal preference is the major criterion to consider. The acceptability, or otherwise, of the displays appears to depend more on the kansei ergonomics, or the subjective opinions of the pleasantness of the overall appearance of the complete unit, than on the physical reflectance and gloss characteristics of the surround. This is exactly the same situation as is found with tablets, such as the ipad and the Google Nexus 7, where a search of the internet reveals that opinions on the colours and glossiness of the surrounds is divided - and presumably the market forces will prevail. Our findings, along with our previous findings (Howarth and Hodder, 2004) and those of Soderston et al. 2003, Hunter et al., 2003, Sheedy et al. 2005 and Hisatake et al. 2011 all indicate that there is no need for standards organizations to impose limits on either the glossiness or the colour of display bezels.

\section{ACKNOWLEDGMENTS}

We gratefully thank the participants for their involvement, and Paul Gensmantel for his help with the data collection. This study was financed entirely by Loughborough University. 


\section{REFERENCES}

Belánd, M.C, Andrén, B. (2007) Effect of gloss and diffuse reflectance of display frames on visual comfort. Journal of the SID, 15 (3), pp. 225-231.

Hisatake, Y., Umezu, N., Kato, C., Nakano, Y. (2011), 31.4: A Preliminary Study on the Frame Glare by Reflected Light for its Allowable Level and Evaluation Method. SID Symposium Digest of Technical Papers, 42: 420-423. doi: 10.1889/1.3621341

Howarth, P.A, Hodder, S.G. (2004) Bezel gloss and glare. Displays 25 (2-3) pp. 77-87.

Hunter, C., Boyce P., Watt, J. (2003). Effect of Bezel Reflectance on People Using a Computer Monitor, HCI International conference, Crete, Greece, June 2003.

KAN (2011) KAN position paper on glossiness of computer monitor and VDT casings.

Kommission Arbeitsschutz und Normung. Downloaded 30 $30^{\text {th }}$ May 2013 from:

http://www.kan.de/fileadmin/user_upload/docs/Fachbeitraege/Articles_EN/KAN_position_paper_on_glossine ss_of_computer_monitor_and_VDT_casings_EN.pdf

Marlow, P., Kim, J. Anderson, B.L. (2011) The role of brightness and orientation congruence in the perception of surface gloss. Journal of Vision August 26, 2011 vol. 11 no. 9 article 16 
Obein, G., Pichereau, T., Harrar, M. Monot, A. Knoblauch, K. Vienot, F. (2004) Does binocular vision contribute to gloss perception? Journal of Vision, November 24, 2004 vol. 4 no. 11 article 73

Overödder, A., Rudling, J. (2003a) TCO Development's Position on Front frame Reflectance. TCOD1027 ver. 1. 2 December 2003

Overödder, A., Rudling J. (2003b) Question about TCO’03: Reply The Ergonomist, May 2003, Number 395, pages 5 and 8

Sheedy, J.E, Smith, R, Hayes, J. (2005) Visual effects of the luminance surrounding a computer display. Ergonomics 48(9) pp. 1113-1128.

Schenkman B., Fukada T., Persson B. (1999) Glare from monitors measured with subjective scales and eye movements. Displays 20: 11-21

Soderston, C., Stewart, A., Clarke, D., Swanson, A., Barnes, J. (2003). Effect of Diffuse Reflectance of Monitor Bezel Color on Human Performance, Preference, and Comfort, SIDS'03 Conference Digest, 2, $832-835$.

TCO’03 Displays “Flat Panel Displays” TCOD1024 Ver 1.0 The Swedish Confederation of Professional Employees, 28 November 2002 
Yan, Z., Hu, L., Chen, H., Lu, F. (2008). Computer Vision Syndrome: A widely spreading but largely unknown epidemic among computer users. Computers in Human Behavior, 24(5), 20262042.

\section{FIGURE CAPTIONS}

Figure 1. The two silver FPDs used in the experiment are shown, illustrating the difference in bezel glossiness

Figure 2. Average responses for each of the 7 questions.

Figure 3. Individual responses to question 3 : "How much visual discomfort did you experience during the trial?" 


\section{TABLES}

\begin{tabular}{|c|c|c|}
\hline FPD & Gloss (60 degrees) & Reflectance (\%) \\
\hline White glossy (WG) & 88.8 & 92 \\
\hline White matt (WM) & 4.5 & 52 \\
\hline Black glossy (BG) & 87.6 & 5.4 \\
\hline Black matt (BM) & 6.8 & 67 \\
\hline Silver glossy (SG) & & 67 \\
\hline Silver matt (SM) & 7.2 & \\
\hline
\end{tabular}

Table 1: FPD bezel gloss and reflectance values. 


\begin{tabular}{|c|c|c|c|c|c|}
\hline 1) Irritated and disturbed & $\begin{array}{l}\mathrm{BG}<\mathrm{BM} \\
\mathrm{BG}<\mathrm{WM} \\
\mathrm{BG}<\mathrm{WG} \\
\mathrm{BG}<\mathrm{SM} \\
\mathrm{BG}<\mathrm{SG}\end{array}$ & & $\mathrm{WM}<\mathrm{SG}$ & & \\
\hline 2) Text legible & & $\mathrm{BM}<\mathrm{SM}$ & & & \\
\hline 3) Visual discomfort & $\begin{array}{l}\mathrm{BG}<\mathrm{WG} \\
\mathrm{BG}<\mathrm{SM}\end{array}$ & $\mathrm{BM}<\mathrm{SM}$ & $\mathrm{WM}<\mathrm{SM}$ & $\mathrm{WG}<\mathrm{SM}$ & $\mathrm{SG}<\mathrm{SM}$ \\
\hline $\begin{array}{l}\text { 4) Visual discomfort } \\
\text { compared with usual } \\
\text { experience }\end{array}$ & $\begin{array}{l}\mathrm{BG}<\mathrm{WM} \\
\mathrm{BG}<\mathrm{WG} \\
\mathrm{BG}<\mathrm{SM} \\
\mathrm{BG}<\mathrm{SG}\end{array}$ & $\mathrm{BM}<\mathrm{SM}$ & & & \\
\hline $\begin{array}{l}\text { 5) Content with } \\
\text { appearance }\end{array}$ & $\begin{array}{l}\mathrm{BG}<\mathrm{BM} \\
\mathrm{BG}<\mathrm{SM} \\
\mathrm{BG}<\mathrm{SG}\end{array}$ & $\mathrm{BM}<\mathrm{SM}$ & $\begin{array}{l}\mathrm{WM}<\mathrm{SM} \\
\mathrm{WM}<\mathrm{SG}\end{array}$ & & \\
\hline 6) Glossiness: pleasant & $\begin{array}{l}\mathrm{BG}<\mathrm{BM} \\
\mathrm{BG}<\mathrm{WM} \\
\mathrm{BG}<\mathrm{WG} \\
\mathrm{BG}<\mathrm{SM} \\
\mathrm{BG}<\mathrm{SG}\end{array}$ & $\mathrm{BM}<\mathrm{SM}$ & & $\mathrm{WG}<\mathrm{SM}$ & $\mathrm{SG}<\mathrm{SM}$ \\
\hline 7) Glossiness: disturbing & $\begin{array}{l}\mathrm{BG}<\mathrm{BM} \\
\mathrm{BG}<\mathrm{WM} \\
\mathrm{BG}<\mathrm{SM} \\
\mathrm{BG}<\mathrm{SG}\end{array}$ & $\mathrm{BM}<\mathrm{SM}$ & $\mathrm{WM}<\mathrm{SM}$ & $\mathrm{WG}<\mathrm{SM}$ & $\mathrm{SG}<\mathrm{SM}$ \\
\hline
\end{tabular}

Table 2: Significantly different subjective preferences $(p \leq 0.05)$ for the different bezels. 


\section{FIGURES}

Figure 1

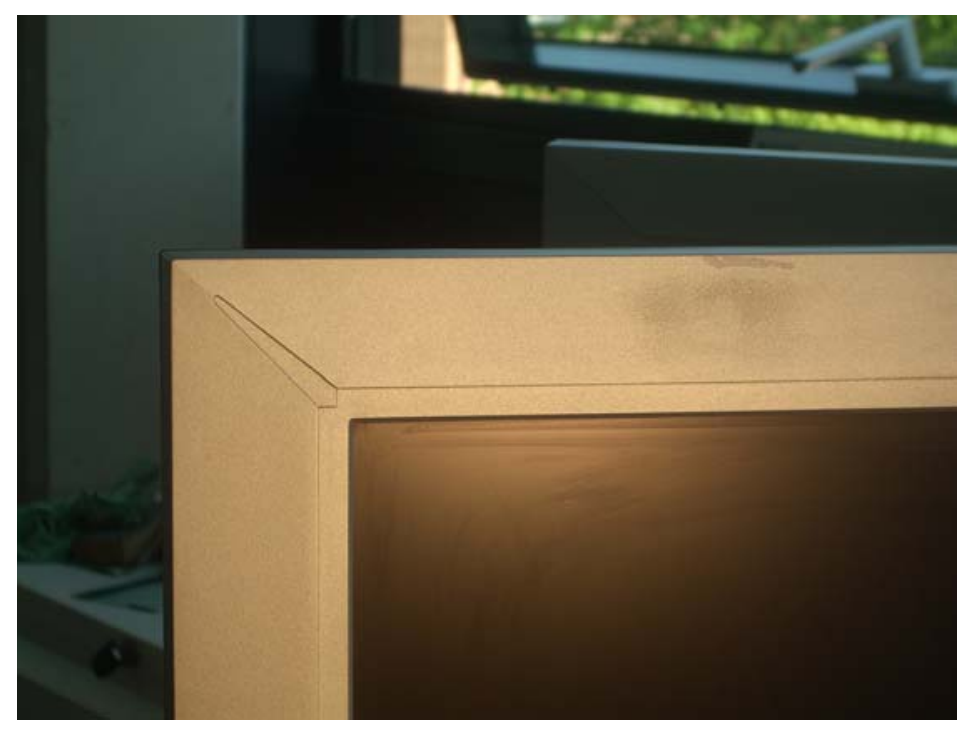




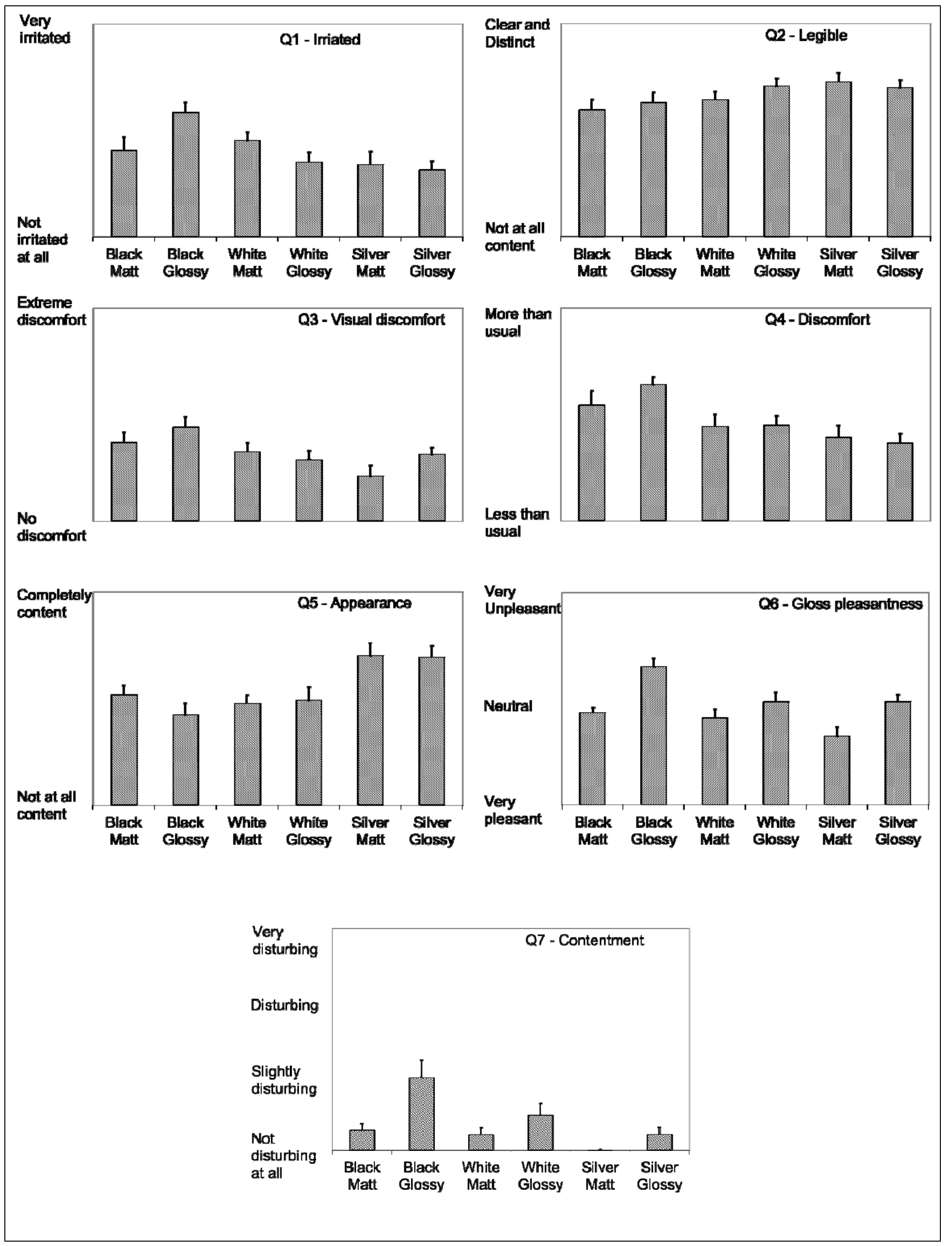


Figure 3

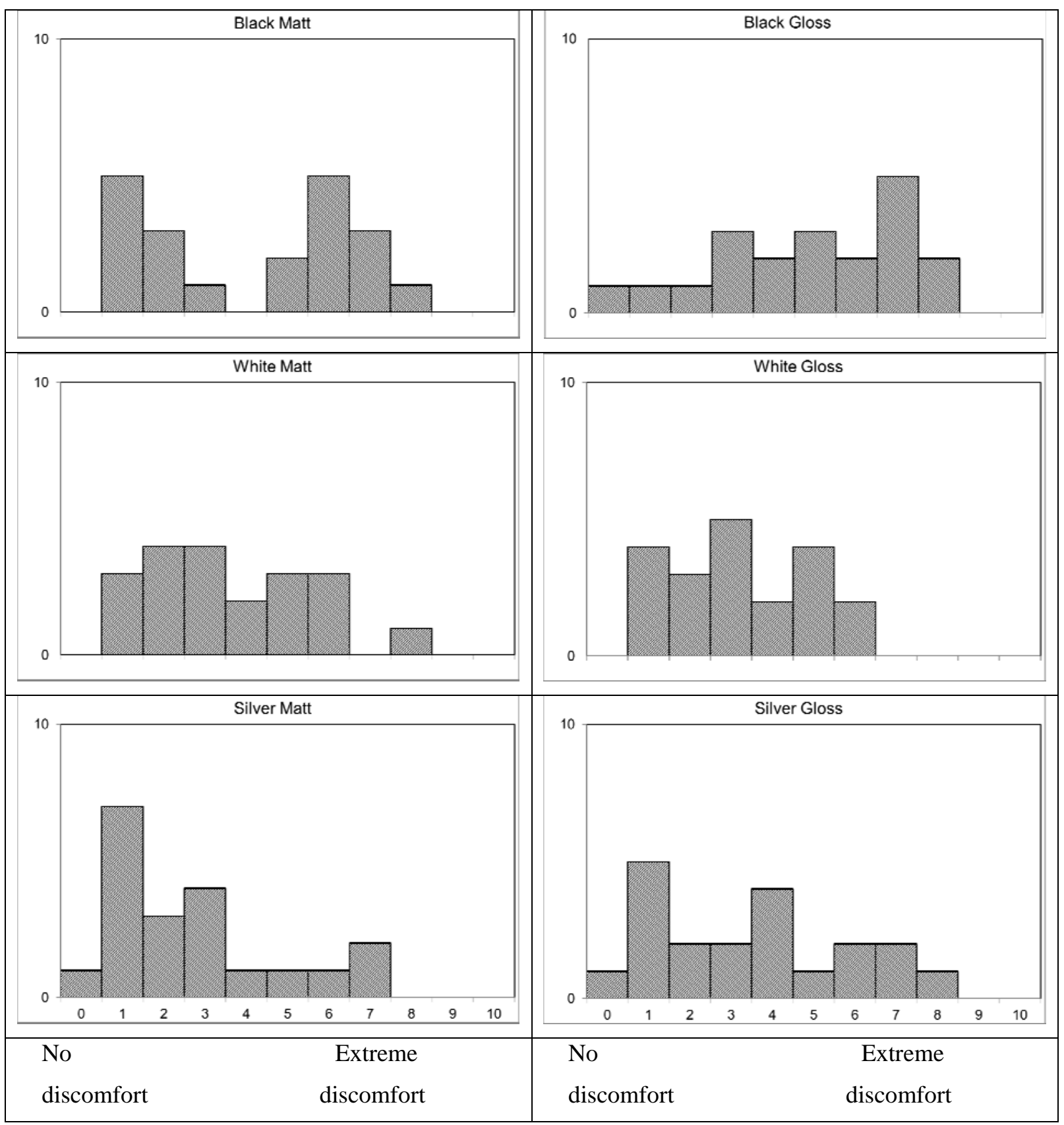


